\title{
The evolutionary neuroscience of tool making
}

\author{
Dietrich Stout $^{\mathrm{a}, *}$, Thierry Chaminade ${ }^{\mathrm{b}}$ \\ ${ }^{a}$ Institute of Archaeology, University College London, 31-34 Gordon Square, London WC1H OPY, UK \\ ${ }^{\mathrm{b}}$ Functional Imaging Lab, Institute of Neurology, University College London, 12 Queen Square, London WC1N 3BG, UK
}

Received 16 June 2006; received in revised form 19 September 2006; accepted 19 September 2006

Available online 30 October 2006

\begin{abstract}
The appearance of the first intentionally modified stone tools over 2.5 million years ago marked a watershed in human evolutionary history, expanding the human adaptive niche and initiating a trend of technological elaboration that continues to the present day. However, the cognitive foundations of this behavioral revolution remain controversial, as do its implications for the nature and evolution of modern human technological abilities. Here we shed new light on the neural and evolutionary foundations of human tool making skill by presenting functional brain imaging data from six inexperienced subjects learning to make stone tools of the kind found in the earliest archaeological record. Functional imaging of this complex, naturalistic task was accomplished through positron emission tomography with the slowly decaying radiological tracer ${ }^{18}$ flouro2-deoxyglucose. Results show that simple stone tool making is supported by a mosaic of primitive and derived parietofrontal perceptual-motor systems, including recently identified human specializations for representation of the central visual field and perception of three-dimensional form from motion. In the naïve tool makers reported here, no activation was observed in prefrontal executive cortices associated with strategic action planning or in inferior parietal cortex thought to play a role in the representation of everyday tool use skills. We conclude that uniquely human capacities for sensorimotor adaptation and affordance perception, rather than abstract conceptualization and planning, were central factors in the initial stages of human technological evolution.
\end{abstract}

(C) 2006 Elsevier Ltd. All rights reserved.

Keywords: Archaeology; Human evolution; Positron emission tomography; IPS; PMC; Prehension; Object manipulation

\section{Introduction}

Tool using and tool making abilities help to define human uniqueness, and have long been a focus in the study of human cognitive evolution. Most recently, this has led to the identification of a shared network of brain regions supporting simple tool use in both monkeys and humans (Johnson-Frey, 2004; Maravita \& Iriki, 2004). However, the neural foundations and evolutionary antecedents of complex, uniquely human tool skills, including tool making, remain poorly known. In this respect, the wealth of chronological, contextual and behavioral evidence provided by the archaeological record of human evolution has all too often

Abbreviations: ANOVA, analysis of variance; BA, Brodmann area; (f)MRI, (functional) magnetic resonance imaging; PET, positron emission tomography; VOI, volume of interest; IPS, intraparietal sulcus; IPTO, intraparietal and transverse occipital sulci; LOC, lateral occipital complex; PMC, premotor cortex; SMA, supplementary motor area

* Corresponding author. Tel.: +44 207679 4742; fax: +44 2073832572.

E-mail address: dietrich.stout@ucl.ac.uk (D. Stout). been neglected (Wynn, 2002). As previously advocated by Toth and Schick (1993), the research presented here integrates evolutionary, archaeological and neuroscientific approaches to human tool use by applying functional brain imaging to the study of the earliest known technology exclusive to the human lineage (hominins).

The first stone tools appear in the archaeological record over 2.5 million years ago (Semaw et al., 1997), roughly concurrent with the origins of genus Homo (Asfaw, White, Lovejoy, Latimer, \& Simpson, 1999; Kimbel et al., 1996; Suwa, White, $\&$ Howell, 1996) and prior to any fossil evidence of significant hominin brain expansion (Holloway, 1999). These earliest human artifacts belong to the Oldowan Industrial Complex, named for Olduvai Gorge, Tanzania, where the technology was first described (Leakey, 1971), and consist of nothing more than sharp-edged stone flakes produced by striking one cobble (the core) with another (the hammerstone) (Fig. 1). Despite their simplicity, Oldowan tools provide the first evidence of the uniquely human (Mithen, 1996; Wynn \& McGrew, 1989) practice of using a tool to make another tool, and constitute a critical 


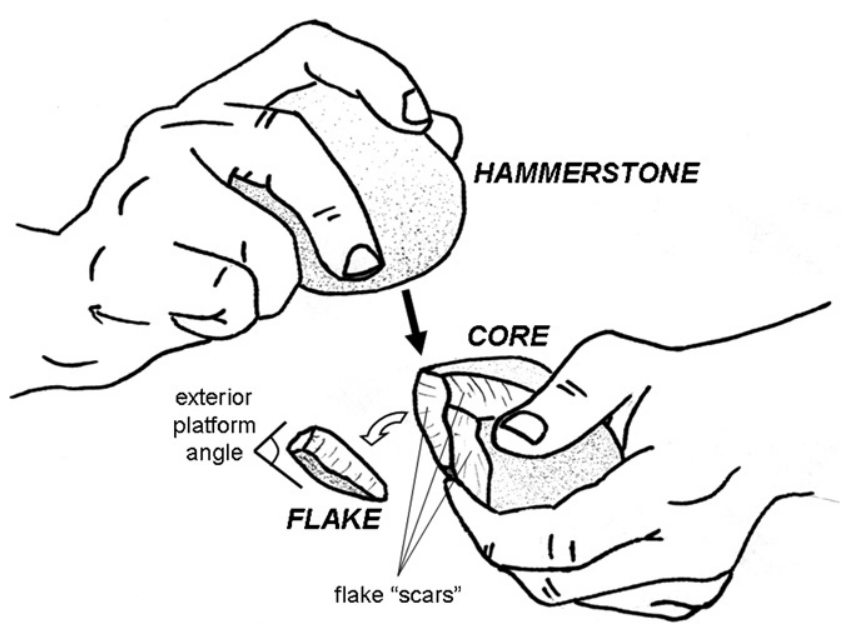

Fig. 1. Oldowan tool making; the hammerstone, held in a characteristic "threejaw chuck" grip with the thumb and first two fingers of the dominant hand, is used to strike sharp stone flakes from the core, which must be properly supported, positioned and oriented by the non-dominant hand. Controlled fracture requires exploitation of appropriate aspects of core morphology, such as acute edge angles (reflected in the exterior platform angles of detached flakes).

adaptive threshold providing their makers with enhanced capabilities to modify bone, wood and other materials and to gain access to high-quality food sources, including meat (Ambrose, 2001). However, it remains controversial whether this behavioral revolution indicates a similar renovation of underlying cognitive capacities (Mithen, 1996; Pelegrin, 2005), or merely the reapplication of preexisting primate capacities in a new context (Wynn \& McGrew, 1989). Identifying what it is that is truly distinctive about the first uniquely human technology would be a key step in addressing questions about the nature and evolutionary origins of modern human technical ability (Johnson-Frey, 2003; Wolpert, 2003).

Oldowan tool making is a complex form of tool use in which one tool is used to modify another object in order to render it efficient for subsequent use as a (secondary) tool. Although conceptually quite simple, it requires both visuomotor skill and an intuitive understanding of stone fracture properties (Ambrose, 2001). In other words, it requires the ability to perceive and exploit highly specific possibilities for action (affordances) presented by the core. Viable flaking surfaces must be selected on the basis of core morphology and high velocity blows directed to precise targets in order to successfully initiate and control fracture (Pelegrin, 2005). Furthermore, successive flake removals leave "scars" (Fig. 1) which alter core morphology in ways that may be used by skilled tool makers to strategically create and/or maintain favorable flaking surfaces.

The experiments presented here were designed to assess the neural correlates of these unique demands of Oldowan tool making. They do not directly address broader issues regarding the initial invention of the technology, nor its practical incorporation into complex behavioral patterns including raw material procurement (Stout, Quade, Semaw, Rogers, \& Levin, 2005), foraging and resource transport strategies (Potts, 1991; Schick, 1987), carcass processing (de Heinzelin et al., 1999), and the possible use of Oldowan tools to make other tools (Mithen, 1996).
Instead, they focus on a particular aspect of Oldowan behavior that is well known archaeologically, relatively amenable to experimental investigation, and which appears to be unique to hominins: the controlled fracture of stone to make sharp-edged tools.

Wild chimpanzees make and use a wide variety of tools, and monkeys can be trained to use simple tools in captivity, yet years of practice have not allowed even the most highly trained, "enculturated" modern apes to equal the abilities seen in the earliest hominin stone tool makers (Schick, Toth, Garufi, Rumbaugh, \& Sevcik, 1999). Does this difference in ability reflect hominin enhancements of pre-existing primate prehension systems (Maravita \& Iriki, 2004), the evolution of novel perceptual-motor specializations for visual analysis (Orban et al., 2006) or manual skill representation (JohnsonFrey, Newman-Norlund, \& Grafton, 2005), or the development of new executive capabilities for causal reasoning (JohnsonFrey, 2003; Wolpert, 2003) and strategic planning (Pelegrin, 2005)?

To address this question, we collected functional brain activation (positron emission tomography) data from six previously inexperienced human subjects making Oldowan tools both before and after completing 4 weekly, $1 \mathrm{~h}$ practice sessions. Tool making tasks were contrasted with a closely matched control task (bimanual percussion without flake production) in order to identify unique demands of Oldowan flake production. Unlike studies of everyday tool use skills, neither condition involved functionally designed artifacts associated with pre-existing semantic or motor knowledge regarding appropriate and efficient use. It was hypothesized that the comparison of tool making versus control would yield activations related to the greater perceptual-motor and conceptual complexity of Oldowan flake production, and that practice would be associated with a redistribution (Kelly \& Garavan, 2005) of activity from association to primary sensorimotor cortices as a result of increased task familiarity.

Task-related activations were expected in the human homologues of parietofrontal systems involved in monkey prehension (Rizzolatti, Luppino, \& Matelli, 1998) and tool use (Obayashi et al., 2001), namely dorsal and ventral premotor cortices (PMC) and the rostral part of the intraparietal sulcus (IPS), with a dominance in the left hemisphere. Activation confined to these regions would indicate that Oldowan tool making in humans relies on the same parietofrontal prehension circuits that support simple tool use in monkeys, whereas activation of additional regions would be indicative of novel task demands and substrates. In evolutionary terms, differences observed in comparison to monkeys might reflect either novel human specializations or shared hominoid (ape and human) conditions. Evidence from comparative neuroanatomy and palaeoneurology can provide some indication of the relative likelihood of these two alternatives; however the lack of relevant activation studies in apes currently precludes more definitive assessment.

For example, two regions in which additional activations might be expected are the higher-order association areas in dorsolateral prefrontal and posterior parietal cortices. Both prefrontal (Deacon, 1997; Rilling \& Insel, 1999; Semendeferi, 
Armstrong, Schleicher, Zilles, \& Van Hoesen, 2001) and posterior parietal (Holloway, 1999; Orban, Van Essen, \& Vanduffel, 2004; Zilles, 2005) cortices have been identified as sites of major expansion and reorganization during human evolution, and are specifically enlarged in humans relative to other hominoids.

Dorsolateral prefrontal cortex is a functionally heterogeneous region associated with executive functions such as working memory, conditional response selection, and inhibition, which are important for strategic action planning. Its activation in the current study would provide evidence of increased demands for domain-general executive functions, such as strategic planning and causal reasoning, during Oldowan tool making.

Posterior parietal cortex, on the other hand, supports sensorimotor integration in monkeys (Rizzolatti et al., 1998) and humans, and was found to be active in an earlier pilot study of Oldowan tool making (Stout, Toth, Schick, Stout, \& Hutchins, 2000). In monkeys, it is subdivided into superior and inferior lobules by the intraparietal sulcus (IPS) (Rizzolatti \& Matelli, 2003), with the superior lobule being preferentially involved in online action control and the inferior lobule in action programming. Although a similar overall organization has been identified in humans, several additional functional regions involved in representation of the central visual field and extraction of threedimensional form from motion have recently been identified in the dorsal part of human IPS (Orban et al., 2006). It has been hypothesized that these new functional regions may contribute to enhanced human capacities for visual analysis during manipulation and tool handling (Orban et al., 2006).

Activation might also be expected in the cerebellum, traditionally viewed as a motor structure but increasingly recognized for its diverse cognitive contributions (Schmahmann, 1997). The lateral cerebellum in particular has been associated with complex movement planning and visuospatial problem solving, among other cognitive functions, and has recently been shown to be preferentially expanded in hominoids (MacLeod, Zilles, Schleicher, Rilling, \& Gibson, 2003). In contrast to prefrontal and posterior parietal cortices, activation of the lateral cerebellum during Oldowan tool making would be most consistent with reliance on pre-existing hominoid specializations, perhaps reflecting a legacy of prior adaptations for versatile arboreal locomotion and extractive foraging (MacLeod et al., 2003).

\section{Methods}

\subsection{Experimental subjects}

Six healthy, right-handed subjects (three male, three female) between 20 and 30 years of age and with no prior stone tool making experience participated in the study. All subjects gave informed written consent. The study was performed in accordance with the guidelines from the declaration of Helsinki and was approved by the Human Subjects Committee at Indiana University, Bloomington. Subjects were paid for their participation.

\subsection{Experimental tasks}

Each subject performed three experimental tasks:

(1) Control: subjects were instructed to forcefully strike together cobbles, selected from an assortment within easy reach on a cart to their left, without attempting to produce flakes.
(2) Tool making, pre-practice: on a subsequent day subjects were instructed to strike together cobbles from the cart in order to produce sharp stone flakes that would be "useful for cutting."

(3) Tool making, post-practice: following the pre-practice session, each subject participated independently in 4 weekly, $1 \mathrm{~h}$ tool making practice sessions. During these practice sessions, subjects were provided with the same general selection of cobbles available during the data collection sessions, as well as sheets of vinyl and pieces of wood with which to test the cutting ability of tools produced. They were not given any additional instructions or practical demonstrations regarding appropriate tool making techniques. Following completion of the practice regime subjects participated in the post-practice session with conditions and instructions identical to those in the pre-practice session. The post-practice condition was defined by completion of the practice regime rather than achievement of set performance criteria.

Subjects performed all tasks comfortably seated in a chair with an array of stone cobbles available within easy reach on a cart to their left. Selection of cobbles from those provided was a component of all tasks. Cobbles were collected at a gravel quarry in Martinsville, Indiana, and included a range of sizes, shapes and materials, primarily limestone, quartzite, and variously metamorphosed basalt (e.g. greenstone). These different materials have very different fracture properties, making raw material selection (Stout et al., 2005) an important factor in successful tool making.

\subsection{Functional imaging}

Use of the relatively slowly decaying radiological tracer ${ }^{18}$ flouro-2deoxyglucose $\left(\left[{ }^{18} \mathrm{~F}\right] \mathrm{FDG}\right)$ allowed for naturalistic task performance outside the confines of the scanner. A venous catheter to administer the tracer was inserted in a vein of the foot. Thirty seconds after the condition started, a $10 \mathrm{mCi}$ bolus of $\left[{ }^{18} \mathrm{~F}\right] \mathrm{FDG}$, produced on-site, was injected. Each task was performed for $40 \mathrm{~min}$, well past the tracer uptake period, and was followed by a 45 min PET scanning session.

Whole brain FDG-PET imaging was performed using an ECAT 951/31 PET scanner (Siemens Medical Systems, Inc., Hoffman Estates, IL) at the Indiana University School of Medicine, Department of Radiology. Sixty-three continuous $128 \times 128$ transaxial images with a slice thickness of $2.43 \mathrm{~mm}$ and an inplane axial resolution of $2.06 \mathrm{~mm}$ (fov: $263.68 \mathrm{~mm} \times 263.68 \mathrm{~mm} \times 153.09 \mathrm{~mm}$ ) were acquired simultaneously with collimating septa retracted operating in $3 \mathrm{D}$ mode. Correction for attenuation was made using a transmission scan collected at the end of each session.

\subsection{Image analysis}

Images were reconstructed and analyzed using standard SPM2 procedures. For each subject, images were realigned to the control condition scan, normalized into the MNI stereotaxic space, and smoothed using a $6 \mathrm{~mm}$ FWHM Gaussian filter convolution. A population main effect model with three conditions (control condition, tool making pre-practice, tool making post-practice) and six subjects was selected, leaving 10 d.f. from 18 images. Linear contrasts assessing differences between the conditions of interest and the control condition were used to create statistical parametric maps, which were thresholded at $p<0.05$ corrected for multiple comparisons using the false discovery rate (Genovese, Lazar \& Nichols, 2002) and extent threshold $k>15$.

In regions of interest, the signal was extracted from approximately 20 voxels using the volume of interest tool in SPM2 and subjected to univariate analysis with SPSS ${ }^{\odot}$. In each case, a 3 (conditions) by 6 (random factor subjects) analysis of variance $(p<0.05)$ was used to test the hypothesis that the signal was modified by experimental conditions, indicating a significant effect of conditions on the activity of both clusters. Paired-sample $t$-tests $(p<0.05)$ assessed differences between pairs of conditions.

\subsection{Artifact analysis}

All artifacts produced during recording sessions were collected and analyzed with respect to typological classification, frequency, technological 
characteristics, mass, linear dimensions, and morphology. Statistical analyses were conducted using SPSS ${ }^{\odot}$.

\section{Results}

\subsection{Tool making performance}

All subjects succeeded in producing recognizable Oldowan artifacts in each tool making session. In agreement with their self-reported right hand preference, all subjects chose to use the right hand for percussion with the hammerstone and the left hand for core support. Details of performance varied according to experience (pre- versus post-practice), individual, raw material, and sex (most likely reflecting upper body strength). A full analysis is beyond the scope of the current article; however flake data pooled across all subjects reveal significant practice effects. Because distributions violated the assumption of normality (Shapiro-Wilk test, $p<0.01$ ), the non-parametric Mann-Whitney test was employed. Practice resulted in decreases in mean flake length $(n=393, Z=-2.380$, $p=0.017)$, thickness $(n=393, Z=-2.305, p=0.021)$, and mass $(n=393, Z=-2.586, p=0.010)$, and in the mean exterior platform angle $(n=304, Z=-2.285, p=0.022)$. The exterior plat-

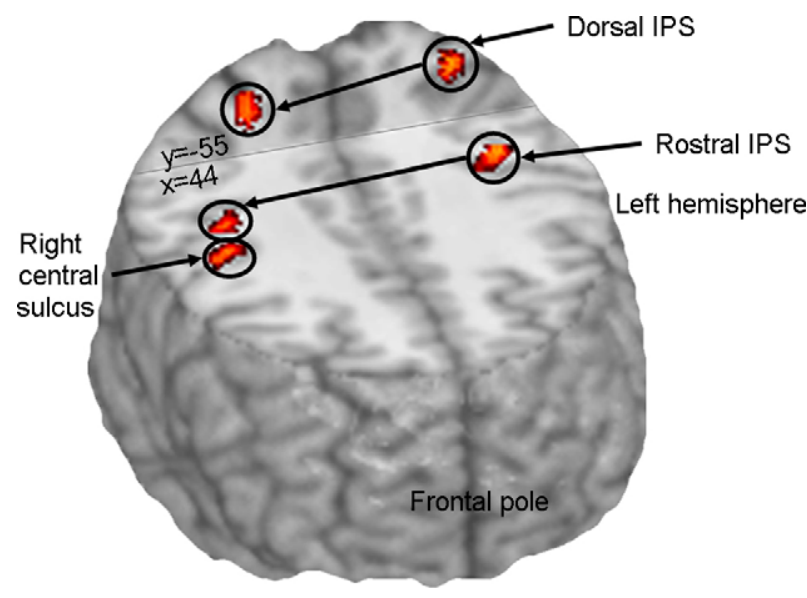

Fig. 2. Intraparietal sulcus activations; standard brain cut-out showing clusters of increased activity within the IPS in the conjunction of pre- and post-practice tool making conditions contrasted with the control condition (thresholds as in Table 1). Coordinates indicate planes used for coronal and horizontal cut-outs.

form angle (Fig. 1) is formed by the intersection of the striking (platform) and exterior (dorsal) surfaces of the detached flake, and provides a measure of the angle of the core edge from which the flake was removed. No significant change

Table 1

Localization of activated clusters at $p<0.05$ FDR-corrected, extent $k>15$

\begin{tabular}{|c|c|c|c|c|c|c|c|c|c|c|c|c|c|}
\hline \multirow[t]{2}{*}{ Localization } & \multirow[t]{2}{*}{$\mathrm{BA}^{\mathrm{a}}$} & \multicolumn{4}{|c|}{ Conjunction } & \multicolumn{4}{|c|}{ Pre-practice } & \multicolumn{4}{|c|}{ Post-practice } \\
\hline & & $x$ & $y$ & $z$ & $T$-score & $x$ & $y$ & $z$ & $T$-score & $x$ & $y$ & $z$ & $T$-score \\
\hline \multicolumn{14}{|c|}{ Frontal cortex (including central sulcus region) } \\
\hline Right postcentral gyrus & 3 & & & & & 38 & -32 & 62 & 5.41 & & & & \\
\hline Left dorsal premotor cortex & 6 & -22 & -4 & 60 & 4.75 & -24 & -6 & 54 & 4.89 & -20 & -4 & 60 & 5.06 \\
\hline Right medial premotor cortex & 6 & & & & & 6 & -2 & 52 & 5.64 & 6 & -2 & 52 & $4.16^{\mathrm{c}}$ \\
\hline Right central sulcus & $3 / 4 / 6$ & 40 & -14 & 50 & 8.92 & 40 & -14 & 50 & 8.92 & 40 & -16 & 48 & 9.44 \\
\hline Left postcentral gyrus & 43 & -56 & -20 & 36 & 5.87 & -56 & -20 & 36 & 5.87 & -56 & -20 & 36 & 7.70 \\
\hline Left ventral premotor cortex & 6 & & & & & -62 & 10 & 32 & 5.86 & & & & \\
\hline Left ventral premotor cortex & 6 & & & & & & & & & -52 & 2 & 30 & 6.12 \\
\hline \multicolumn{14}{|l|}{ Parietal cortex } \\
\hline Left intraparietal sulcus & $7 / 40$ & -34 & -56 & 62 & 5.60 & -34 & -56 & 62 & 6.00 & -28 & -60 & 60 & 6.16 \\
\hline Right intraparietal sulcus & $7 / 40$ & 22 & -54 & 56 & 5.20 & 22 & -54 & 56 & 5.20 & 22 & -54 & 56 & 5.20 \\
\hline Left superior parietal lobule & 7 & -24 & -62 & 54 & 5.79 & -24 & -62 & 54 & 5.79 & -24 & -62 & 54 & 7.04 \\
\hline Right intraparietal sulcus & 40 & 34 & -32 & 46 & 4.56 & 34 & -32 & 46 & 4.56 & 34 & -32 & 46 & 5.07 \\
\hline Left intraparietal sulcus & 40 & -40 & -38 & 42 & 6.18 & -42 & -40 & 44 & 6.86 & -40 & -38 & 42 & 6.18 \\
\hline \multicolumn{14}{|l|}{ Occipital cortex } \\
\hline Right middle occipital gyrus & 19 & & & & & & & & & 30 & -64 & 32 & 5.71 \\
\hline Left middle occipital gyrus & 19 & & & & & & & & & -32 & -68 & 28 & 6.51 \\
\hline Left superior occipital gyrus & 18 & -20 & -86 & 28 & 5.49 & -20 & -86 & 28 & 5.49 & -20 & -86 & 26 & 6.62 \\
\hline Right superior occipital gyrus & 18 & 18 & -94 & 20 & 5.71 & 18 & -94 & 20 & 5.74 & 18 & -94 & 20 & 5.71 \\
\hline Right calcarine sulcus & 17 & 16 & -78 & 10 & 7.84 & 16 & -78 & 12 & 8.18 & 16 & -78 & 10 & 8.51 \\
\hline Left calcarine sulcus & 17 & -14 & -70 & 8 & 5.55 & -14 & -70 & 8 & 5.55 & -16 & -72 & 6 & 6.30 \\
\hline Right calcarine sulcus & 18 & 28 & -80 & 8 & 6.19 & 28 & -80 & 8 & 6.19 & 28 & -78 & 6 & 7.22 \\
\hline Left inferior occipital gyrus & 19 & & & & & & & & & -34 & -70 & -8 & 7.04 \\
\hline Right lingual gyrus & 18 & 20 & -76 & -8 & 5.88 & 18 & -72 & -12 & 6.31 & 20 & -76 & -10 & 5.25 \\
\hline Right fusiform gyrus & 19 & & & & & & & & & 26 & -58 & -10 & 5.86 \\
\hline \multicolumn{14}{|l|}{ Cerebellum } \\
\hline Left cerebellar hemisphere & $4 / 5 / 6^{\mathrm{b}}$ & -10 & -52 & -14 & 6.58 & -10 & -52 & -14 & 8.54 & -10 & -52 & -14 & 6.58 \\
\hline Cerebellar vermis & $5 / 6^{\mathrm{b}}$ & & & & & 0 & -58 & -24 & 7.07 & & & & \\
\hline
\end{tabular}

\footnotetext{
a Brodmann area for cerebral clusters.

b Cerebellum clusters follow conventions from (Schmahmann, Doyon, Toga, Petrides, \& Evans, 2000).

c Activity in this cluster covers one voxel and is found in the absence of extent threshold.
} 

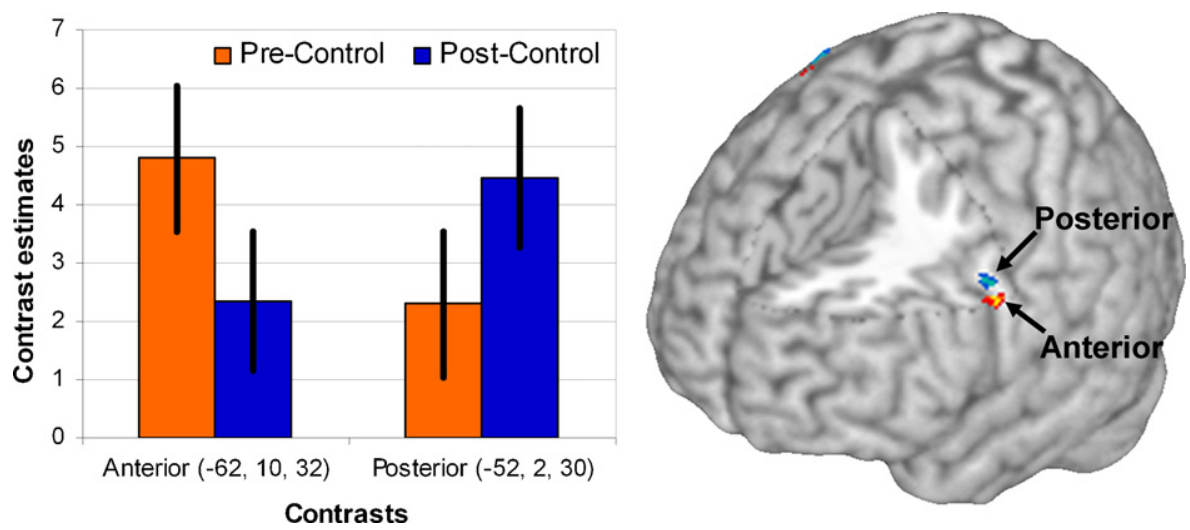

Fig. 3. Ventral PMC activations. Right: clusters of increased activity in contrasts of pre-practice (hot scale) and post-practice conditions (cold scale) with the control condition. Left: plot of contrast estimates (error bar: $90 \%$ confidence interval) from the ventral PMC clusters showing an interaction between cluster location and condition.

was seen in the number of flakes produced per subject or per cobble.

\subsection{PET results}

In four subjects cerebellum was incompletely scanned, so that no conclusion regarding ventral cerebellar activity can be reached with the present data. Table 1 gives results for the two contrasts of interest: making tools before practice compared to control (pre-practice) and making tools after practice compared to control (post-practice) as well as the conjunction between the two contrasts, indicating regions activated in both contrasts. Clusters of increased activity in both contrasts were found in the left dorsal PMC and right central sulcus regions covering premotor, primary motor and somatosensory cortices, as well as regions spanning the parietal cortex around the intraparietal sulcus (Fig. 2) and early visual areas bilaterally. No dorsolateral prefrontal cortex activity was found, even when the contrasts were thresholded with the lenient $p<0.01$ uncorrected. Regions found in only one of the contrasts of interest, and absent in the conjunction analysis, include the right medial PMC and post-central gyrus (pre-practice), higher-order visual areas (post-practice), and left ventral premotor cortex (differentially activated in the two contrasts).
Activity from the ventral PMC clusters was extracted, with 18 voxels for the pre-practice cluster $(x, y, z,=-62,10,32)$ and 20 voxels for the post-practice cluster $(-52,2,30)$. ANOVA indicated a significant effect of conditions on the activity of both clusters. All comparisons between activity in pairs of conditions were significant at $p<0.05$ except the difference between preand post-practice in the anterior cluster, in hot colors on Fig. 3 $(p=0.1)$. SPM2 estimates for contrasts between conditions of interest and the control condition in the two ventral premotor cortices are given in Fig. 3. A three-way ANOVA (condition: pre- and post-practice, location: anterior and posterior cluster in the ventral PMC, random effect: subjects) on contrast estimates derived from extracted VOI confirmed that the interaction between location and condition, clearly visible on the graph, is statistically significant, in the absence of significant main effects from the factors taken individually. These results strongly suggest that the brain activity in these two ventral PMC clusters is modulated by practice.

Table 1 shows that clusters in ventral, lateral and dorsal higher-order visual areas within Brodmann area 19 (BA 19) are significantly activated after but not before practice. Activity in the left inferior occipital gyrus was extracted using a $3.5 \mathrm{~mm}$ spherical VOI (19 voxels) around the cluster maximum $(x, y, z=-34,-70,-8)$. A subject by condition ANOVA
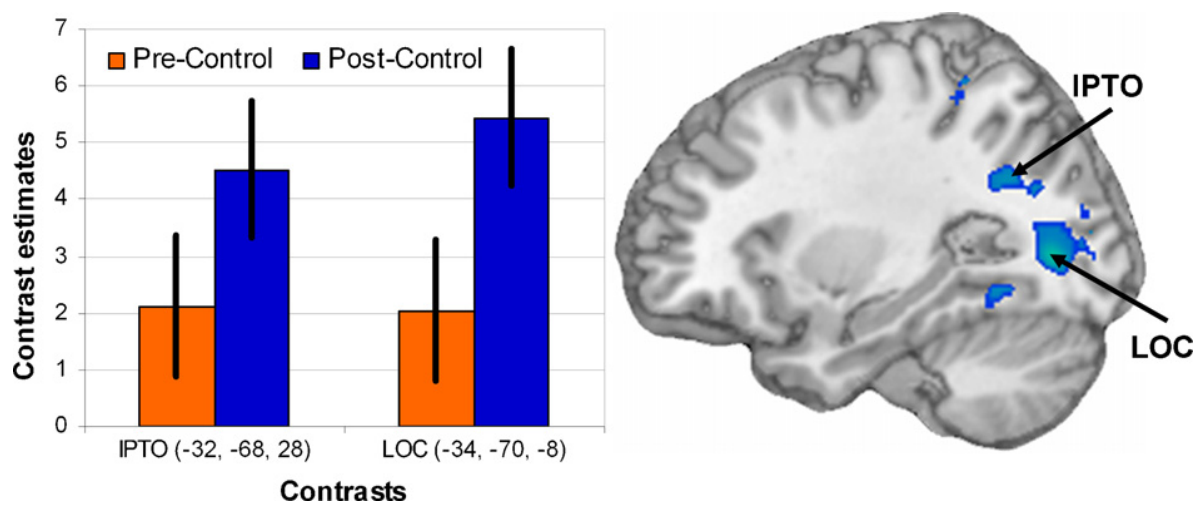

Fig. 4. Occipital cortex activations. Right: clusters of increased activity in contrast of post-practice with control (cold scale) rendered on a sagittal section. Left: plot of contrast estimates (error bar: 90\% confidence interval) in the ventral (LOC) and dorsal (IPTO) occipital areas reveal a main effect of practice. 
indicated a significant effect of conditions on the activity $\left(F_{2,18}=20.4\right)$, and all comparisons between activity in pairs of conditions were significant. A similar analysis was performed for the cluster in the left middle occipital gyrus ( $x$, $y, z=-32,-68,28,3 \mathrm{~mm}$ spherical VOI, 20 voxels), which yielded the same results $\left(F_{2,18}=18.6\right)$. Brain activity in these occipital regions thus shows a progressive increase across the three conditions: control, tool-making before practice and toolmaking after practice, as shown by SPM2 contrast estimates for pre-practice and post-practice compared to control (see Fig. 4).

\section{Discussion}

Functional imaging studies with modern humans cannot directly reveal the mental capacities of pre-human ancestors, but can shed light on the relative demands of evolutionarily significant tasks. The research presented here develops new methods for the experimental investigation of such tasks by employing the relatively slowly decaying radiological tracer ${ }^{18}$ flouro-2deoxyglucose to image complex, naturalistic tool making behavior conducted outside the scanner. It should be noted that the unusual commitment of time and effort required of subjects by this methodology, coupled with the relatively high level of radiation exposure associated with FDG-PET, imposes limitations on both the number of subjects and the number of scans per subject. However, in the present study the FDG-PET procedure yielded a very large signal to noise ratio sufficient for statistical analysis. In particular, contrasts of Oldowan tool making with simple bimanual percussion revealed significant $(p<0.05$ FDRcorrected) premotor, parietal and occipital activations indicative of the greater sensorimotor, spatial, and attentional demands of the tool making task.

\subsection{Sensorimotor activations}

As predicted, activations were observed in rostral IPS and ventral PMC areas homologous to those which support prehension (Rizzolatti et al., 1998) and simple tool use (Obayashi et al., 2001) in monkeys. The most rostral IPS clusters activated during Oldowan tool making (Fig. 2) are located bilaterally at the junction of the intraparietal and postcentral sulci. This region has been characterized as homologous to the anterior intraparietal region of the monkey due to its involvement in visually guided grasping (Frey, Vinton, Norlund, \& Grafton, 2005) and visuo-tactile information transfer (Grefkes, Weiss, Zilles, \& Fink, 2002). Ventral PMC activation during tool making is located in left anterior Brodmann area 6, bordering area 44 , in a region which has been identified as homologous to monkey area 6 (specifically F5) on the basis of sulcal anatomy (Rizzolatti et al., 1998), quantitative architectonics and electrophysiological response characteristics (Petrides, Cadoret, \& Mackey, 2005). These ventral PMC and rostral IPS activations during Oldowan tool making indicate continued reliance on an evolutionarily conserved cortical system that performs sensorimotor transformations for object manipulation (Maravita \& Iriki, 2004; Rizzolatti et al., 1998).

However, additional clusters of activation were also observed bilaterally in more dorsal IPS (Fig. 2), providing evidence of novel task demands and substrates, and supporting the hypothesis that a broader suite of cortical regions played a role in the evolution of uniquely human tool making capacities. These clusters overlap with the phylogenetically recent functional areas identified by Orban and colleagues (Orban et al., 2006; Orban, Sunaert, Todd, Van Hecke, \& Marchal, 1999), although the spatial resolution of PET and inter-subject anatomical variability preclude more precise localization. These new functional areas, not found in the monkey, provide additional central visual field representations and increased sensitivity to the extraction of three-dimensional form from motion (Orban et al., 2006). Preferential recruitment of this region by Oldowan toolmaking (Fig. 2) most likely reflects demands for detailed analysis of the threedimensional shape and orientation of the core during tool making. Successful flaking requires visual identification of suitable targets on the core, which is supported and rotated in the left hand for close examination before and during percussion (Pelegrin, 2005). Orban and colleagues (Orban et al., 2006) have proposed that the new functional areas in human dorsal IPS may provide enhanced capacities for visual analysis during object manipulation and tool handling. Activation of this region in the current study corroborates this hypothesis and indicates that visuomotor specializations in human posterior parietal cortex play an important role in supporting Oldowan tool making ability.

Unfortunately, a lack of evidence regarding the functional organization of posterior parietal cortex in other hominoids means that it is not currently possible to specify whether these adaptations are specific to humans or shared by hominoids more generally. The well known expansion of posterior parietal cortex in humans relative to other hominoids (Holloway, 1999), coupled with recent fossil evidence showing reorganization of this area in a specimen of Australopithecus broadly coeval $(\sim 2.8-2.3$ million years old) with the first stone tools (Holloway, Clarke, $\&$ Tobias, 2004), does provide at least circumstantial support for the likelihood of hominin-specific adaptations. However, definitive identification of such adaptations will have to await more detailed functional mapping of hominoid posterior parietal cortex.

Activations observed in the supplementary motor area of the medial PMC, in the cerebellum and in primary sensorimotor cortices further attest to the complex motor organization of Oldowan tool making, which requires the coordination of cobble support, positioning and orientation in the non-dominant hand with accurate, high velocity strikes by the dominant hand. The supplementary motor area has long been associated with bimanual coordination (Laplane, Talairach, Meiniger, Bancaud, \& Orogogozo, 1977), and more recently has been identified as a key component in a distributed network for interlimb coordination that also includes regions of cerebellar vermis and hemisphere (Debaere et al., 2001) comparable to those activated here. The cluster in cerebellar hemisphere is located in the left anterior lobe, a structure associated with motor execution, and is unlikely to belong to the phylogenetically expanded lateral cere- 
bellum (MacLeod et al., 2003), which is believed to contribute to higher cognitive functions (Schmahmann, 1996).

In the cerebral cortex, activation in the left primary somatosensory area corresponding to the thumb and first two fingers of the dominant hand reflects increased stimulation of digits involved in the characteristic "three-jaw chuck" grip (Fig. 1) used in stone tool making (Marzke et al., 1998). In the right hemisphere, a much larger cluster of activity is seen covering the dorsal part of primary motor and somatosensory cortex where left upper limb movements are controlled. Together with the aforementioned activation in the dorsal IPS relating to examination of the hand-held core, and the preferential recruitment of left anterior cerebellar hemisphere, this lateralized pattern calls attention to the active and essential role of the "support" hand, wrist and arm in Oldowan tool making (Pelegrin, 2005), a characteristic which distinguishes the task from the anvil-based percussive tool use of chimpanzees (Marchant \& McGrew, 2005; Pelegrin, 2005).

Despite this motor complexity, activation was not observed in regions of the inferior parietal lobule linked to the representation of everyday tool use skills (Johnson-Frey et al., 2005). This may indicate that recruitment of the kind of stored motor programs for action planning associated with the use of familiar, functionally designed tools is not a particularly salient demand of Oldowan tool making. Similarly absent was any significant activation in dorsolateral prefrontal cortex, suggesting that Oldowan tool making does not place exceptional demands on executive functions, such as working memory, conditional response selection and inhibition, which are involved in strategic planning. Alternatively, subjects in the current study may not have achieved a sufficient level of skill to recruit these regions and processes. Additional research with expert tool makers, currently in progress, will assess the possible involvement of stored motor representations and prefrontal executive functions in such higher-level performance, and in more advanced lithic technologies.

\subsection{Practice effects}

Effective tool use is achieved through practice. Stone tool making in particular requires mastery of basic flake removal techniques, including visual assessment of cobble composition and morphology, selection of appropriate targets, use of efficient postures and grips, and the planning and execution of accurate percussion. Results of artifact analysis show that subjects in the current study adapted to the tool making task by targeting significantly more acute platform angles and consequently producing shorter, thinner, and less massive flakes. This strategy facilitates successful flaking by reducing the force required to initiate fracture (Dibble \& Pelcin, 1995; Stout, 2002) and tends to yield small flakes that are sharp and immediately useful, but not durable or easily held during more extended, heavy-duty use. This strategy also tends to result in the progressive rounding of core edges, preventing the strategic maintenance of flaking surfaces and exhaustive core reduction through large flake removals that is characteristic of skilled Oldowan flaking in prehistory (Delagnes \& Roche, 2005).
Inexperienced subjects in the current study were clearly challenged by the basic perceptual-motor demands of the task, and pursued a proximal solution to the problem of controlled flake production. This initial stage of perceptual-motor skill acquisition is characterized by a developing emphasis on the visual identification and accurate targeting of appropriate $\left(\sim 80^{\circ}\right)$ core angles, a fact which is reflected by superior parietal and occipital lobe activations relating to the allocation of visual attention (Büchel et al., 1998; Friston \& Büchel, 2000).

Following practice, however, additional activations are seen in higher order visual association areas of the middle and inferior occipital gyri (Fig. 4). These regions are located in the dorsal and ventral streams of visual processing which contribute to the visual control of action and the perception of objects, respectively (Milner \& Goodale, 1995). The left inferior occipital gyrus cluster probably corresponds to the lateral occipital complex (LOC) of the ventral stream, known to respond to the visual presentation of recognizable objects (Grill-Spector, Kourtzi, \& Kanwisher, 2001). The coordinates of the bilateral middle occipital gyrus clusters suggest they may be located at the junction of the caudal intraparietal and transverse occipital sulci (IPTO), a visual area that is strongly modulated by shifts in spatial attention and which plays an important role in visual search for targets defined by the conjunction of multiple features (e.g. color and orientation) (Donner et al., 2000). Both activations likely reflect increased attention to locating and identifying technologically relevant elements of core shape, including appropriate platform angles. In other words, they reflect an education of attention (Gibson, 1979) to newly discovered technological affordances (possibilities for action) of the core.

Such affordances do not exist in isolation, but are instead defined as properties of organism-environment interactions (Grezes \& Decety, 2002). As such, they are critically dependant on the presence of stable and efficient bodily postures, grips and gestures (Smitsman, Cox, \& Bongers, 2005). This is reflected in significant practice effects in ventral PMC, where practice resulted in a significant posterior-medial shift in the centre of activity (Fig. 3). Canonical neurons in monkey ventral PMC (area F5) selectively encode appropriate grasping responses to visually presented objects (Rizzolatti et al., 1998), putatively using information provided by the rostral IPS to derive object affordances (Fagg \& Arbib, 1998). In humans, the visual presentation of graspable tools has been shown to activate left ventral PMC (Chao \& Martin, 2000), in the same location observed in the current experiment. As with the occipital activity discussed above, the practice-mediated shift of ventral PMC activity reflects a functional reorganization (Kelly \& Garavan, 2005) resulting from a change of strategy in response to task constraints, this time in relation to the way the hammerstone and core are handled.

It is also interesting to note that the observed ventral PMC activity is located within the caudal, "phonological" portion of the language-relevant cortex of the left inferior frontal cortex (i.e. Broca's area in the broad sense [Hagoort, 2005]). This region is homologous to macaque area F5 (Petrides et al., 2005), where the discovery of mirror neurons responsive to both the execution and the observation of hand actions has revived longstanding 
speculations about possible evolutionary links between tool use, gesture and language origins (Rizzolatti \& Arbib, 1998). Activation in caudal Broca's area during Oldowan tool making provides further support for the hypothesis that language and tool use depend on similar mechanisms for hierarchical information processing (Greenfield, 1991). Although reliance on shared neural substrates does not demonstrate evolutionary cause and effect, results presented here are consistent with the possibility that early stone tool making favored adaptations later incorporated into an evolving language capacity.

\subsection{Conclusions}

Both behavioral and brain activation data indicate that the initial stages of Oldowan tool making skill acquisition are primarily concerned with perceptual-motor adaptation to task constraints and especially the discovery and exploitation of object affordances, rather than with executive planning and problem solving. Of particular note are: (1) activation of an evolutionarily conserved object manipulation circuit including the rostral part of IPS and ventral PMC (Obayashi et al., 2001; Rizzolatti et al., 1998); (2) recruitment of a more phylogenetically recent region of the dorsal IPS, which has been hypothesized to support uniquely human manipulative and tool-using capabilities (Orban et al., 2006); (3) modulation by practice of activity relating to visual search (caudal intraparietal/transverse occipital sulci), object recognition (lateral occipital cortex), and grip selection (ventral PMC); (4) lack of any activation in dorsolateral prefrontal cortex relating to strategic action planning.

These findings corroborate previous ethnographic research on stone working (Roux, Bril, \& Dietrich, 1995; Roux \& David, 2005; Stout, 2002) showing that higher order strategic organization necessarily emerges from perceptual-motor foundations established through effortful practice. In monkeys as well, initial tool use training is a lengthy process involving modification of bodily representations in the rostral part of IPS, whereas subsequent application of this skill to solve a problem in a novel functional situation is rapidly mastered through apparent transfer and insight learning supported by prefrontal cortex (Maravita $\&$ Iriki, 2004). This suggests that it may be acquisition of the necessary sensorimotor capabilities, rather than executive capacities for strategic planning, that represents the critical bottleneck in the initial development of complex tool use and tool making abilities. Because the acquisition of such sensorimotor capabilities clearly depends upon a combination of neural preconditions with motivated and effortful practice (Iriki, 2005), this conclusion raises questions about the social context necessary to support prolonged perceptual-motor skill acquisition in early hominin toolmakers (Stout, 2005) and provides some support for hypotheses emphasizing the cultural foundations of human technological capabilities (Tomasello, 1999; van Schaik, Deaner, \& Merrill, 1999).

\section{Acknowledgements}

We thank Atsushi Iriki and Chris Frith for comments on an early draft of this paper; Nicholas Toth, Kathy Schick,
Julie Stout, Gary Hutchins and Richard Fain for support and advice; PET technologists Kevin Perry and Susan Geiger; Stuart Laidlaw for help in producing Fig. 1. Funding was provided by the L.S.B. Leakey Foundation, National Science Foundation Grant BCS-0105265, and the Center for Research into the Anthropological Foundations of Technology (CRAFT) at Indiana University.

\section{References}

Ambrose, S. (2001). Paleolithic technology and human evolution. Science, 291, 1748-1753.

Asfaw, B., White, T., Lovejoy, O., Latimer, B., \& Simpson, S. (1999). Australopithecus garhi: A new species of early hominid from Ethiopia. Science, 284(5414), 629-634.

Büchel, C., Josephs, O., Rees, G., Turner, R., Frith, C. D., \& Friston, K. J. (1998). The functional anatomy of attention to visual motion: A functional MRI study. Brain, 121, 1281-1294.

Chao, L. L., \& Martin, A. (2000). Representation of manipulable man-made objects in the dorsal stream. NeuroImage, 12(4), 478-484.

de Heinzelin, J., Clark, J. D., White, T., Hart, W., Renne, P., WoldeGabriel, G., Beyene, Y., \& Vrba, E. (1999). Environment and behavior of 2,5-millionyear-old Bouri hominids. Science, 284, 625-629.

Deacon, T. W. (1997). The symbolic species: The co-evolution of language and the brain. New York: W.W. Norton.

Debaere, F., Swinnen, S. P., Béatse, E., Sunaert, S., Van Hecke, P., \& Duysens, J. (2001). Brain areas involved in interlimb coordination: A distibuted network. NeuroImage, 14, 947-958.

Delagnes, A., \& Roche, H. (2005). Late Pliocene hominid knapping skills: The case of Lokalalei 2C, West Turkana, Kenya. Journal of Human Evolution, 48(5), 435-472.

Dibble, H., \& Pelcin, A. (1995). The effect of hammer mass and velocity on flake mass. Journal of Archaeological Science, 22, 429-439.

Donner, T., Kettermann, A., Diesch, E., Ostendorf, F., Villringer, A., \& Brandt, S. A. (2000). Involvement of the human frontal eye field and multiple parietal areas in covert visual selection during conjunction search. European Journal of Neuroscience, 12(9), 3407-3414.

Fagg, A. H., \& Arbib, M. A. (1998). Modeling parietal-premotor interactions in primate control of grasping. Neural Networks, 11(7-8), 12771303.

Frey, S. H., Vinton, D., Norlund, R., \& Grafton, S. T. (2005). Cortical topography of human anterior intraparietal cortex active during visually guided grasping. Cognitive Brain Research, 23, 397-405.

Friston, K. J., \& Büchel, C. (2000). Attentional modulation of effective connectivity from V2 to V5/MT in humans. Proceedings of the National Academy of Sciences, 97(13), 7591-7596.

Genovese, C. R., Lazar, N., \& Nichols, T. E. (2002). Thresholding of statistical maps in functional neuroimaging using the false discovery rate. NeuroImage, 15(4), 870-878.

Gibson, J. J. (1979). The ecological approach to visual perception. Boston: Houghton-Mifflin.

Greenfield, P. M. (1991). Language, tools, and brain: The development evolution of hierarchically organized sequential behavior. Behavioral and Brain Sciences, 14, 531-595.

Grefkes, C., Weiss, P. H., Zilles, K., \& Fink, G. R. (2002). Crossmodal processing of object features in human anterior intraparietal cortex: An fMRI study implies equivalencies between humans and monkeys. Neuron, 35, 173 184.

Grezes, J., \& Decety, J. (2002). Does visual perception of object afford action? Evidence from a neuroimaging study. Neuropsychologia, 40, 212 222.

Grill-Spector, K., Kourtzi, Z., \& Kanwisher, N. (2001). The lateral occipital complex and its role in object recognition. Vision Research, 41(10-11), 1409-1422.

Hagoort, P. (2005). On Broca, brain, and binding: A new framework. Trends in Cognitive Science, 9(9), 416-423. 
Hewes, G. W. (1973). Primate communication and the gestural origins of language. Current Anthropology, 14, 5-24.

Holloway, R. (1999). Evolution of the human brain. In A. Lock, \& C. R. Peters (Eds.), Handbook of human symbolic evolution (pp. 74-125). Malden, MA: Blackwell Publishers Inc.

Holloway, R., Clarke, R. J., \& Tobias, P. V. (2004). Posterior lunate sulcus in Australopithecus africanus: Was Dart right? Comptes Rendus Palevol, 3 , 287-293.

Iriki, A. (2005). A prototype of Homo faber: A silent precursor of human intelligence in the tool-using monkey brain. In S. Dehaene, J.-R. Duhamel, M. D. Hauser, \& G. Rizzolatti (Eds.), From monkey brain to human brain: A Fyssen Foundation symposium (pp. 253-271). Cambridge, MA: MIT Press.

Johnson-Frey, S. (2003). What's so special about human tool use? Neuron, 39, 201-204.

Johnson-Frey, S. H. (2004). The neural bases of complex tool use in humans. Trends in Cognitive Sciences, 8(2), 71-78.

Johnson-Frey, S. H., Newman-Norlund, R., \& Grafton, S. T. (2005). A distributed left hemisphere network active during planning of everyday tool use skills. Cerebral Cortex, 15(6), 681-695.

Kelly, A. M., \& Garavan, H. (2005). Human functional neuroimaging of brain changes associated with practice. Cerebral Cortex, 15(8), 1089-1102.

Kimbel, W. H., Walter, R. C., Johanson, D. C., Reed, K. E., Aronson, J. L., Assefa, Z., et al. (1996). Late Pliocene Homo and Oldowan tools from the Hadar formation (Kada Hadar Member), Ethiopia. Journal of Human Evolution, 31, 549-561.

Laplane, D., Talairach, J., Meiniger, V., Bancaud, J., \& Orogogozo, J. M. (1977). Clinical consequences of corticectomies involving the supplementary motor area in man. Journal of Neurological Science, 34, 301-314.

Leakey, M. D. (1971). Olduvai Gorge, Volume 3: Excavations in beds I and II, 1960-1963. New York: Cambridge University Press.

MacLeod, C. E., Zilles, K., Schleicher, A., Rilling, J. K., \& Gibson, K. R. (2003). Expansion of the neocerebellum in Hominoidea. Journal of Human Evolution, 44, 401-429.

Maravita, A., \& Iriki, A. (2004). Tools for the body (schema). Trends in Cognitive Sciences, 8(2), 79-86.

Marchant, L., \& McGrew, W. (2005). Percussive technology: Chimpanzee baobab smashing and the evolutionary modelling of hominin knapping. In V. Roux, \& B. Bril (Eds.), Stone knapping: The necessary conditions for a uniquely hominin behavior (pp. 341-350). Cambridge: McDonald Institute for Archaeological Research.

Marzke, M. W., Toth, N., Schick, K., Reece, S., Steinberg, B., Hunt, K., et al. (1998). EMG study of hand muscle recruitment during hard hammer percussion manufacture of Oldowan tools. American Journal of Physical Anthropology, 105(3), 315-332.

Milner, A. D., \& Goodale, M. A. (1995). The visual brain in action. Oxford: Oxford University Press.

Mithen, S. (1996). The prehistory of the mind: The cognitive origins of art, religion and science. London: Thames and Hudson Ltd.

Obayashi, S., Suhara, T., Kawabe, K., Okauchi, T., Maeda, J., Akine, Y., et al. (2001). Functional brain mapping of monkey tool use. NeuroImage, 14(4), $853-861$.

Orban, G. A., Claeys, K., Nelissen, K., Smans, R., Sunaert, S., Todd, J. T., et al. (2006). Mapping the parietal cortex of human and non-human primates. Neuropsychologia, 44, 2647-2667.

Orban, G. A., Sunaert, S., Todd, J. T., Van Hecke, P., \& Marchal, G. (1999). Human cortical regions involved in extracting depth from motion. Neuron, 24, 929-940.

Orban, G. A., Van Essen, D., \& Vanduffel, W. (2004). Comparative mapping of higher visual areas in monkeys and humans. Trends in Cognitive Science, 8 , $315-324$.

Pelegrin, J. (2005). Remarks about archaeological techniques and methods of knapping: Elements of a cognitive approach to stone knapping. In V. Roux, $\&$ B. Bril (Eds.), Stone knapping: The necessary conditions for a uniquely human behaviour (pp. 23-34). Cambridge: McDonald Institute for Archaeological Research.

Petrides, M., Cadoret, G., \& Mackey, S. (2005). Orofacial somatomotor responses in the macaque monkey homologue of Broca's area. Nature, 435(30), 1235-1238.
Potts, R. (1991). Why the Oldowan? Plio-Pleistocene toolmaking and the transport of resources. Journal of Anthropological Research, 47(2), 153-176.

Rilling, J. K., \& Insel, T. R. (1999). The primate neocortex in comparative perspective using magnetic resonance imaging. Journal of Human Evolution, $37,191-223$

Rizzolatti, G., \& Arbib, M. A. (1998). Language within our grasp. Trends in Cognitive Science, 21(5), 188-194.

Rizzolatti, G., Luppino, G., \& Matelli, M. (1998). The organization of the cortical motor system: New concepts. Electroencephalography and Clinical Neurophysiology, 106(4), 283-296.

Rizzolatti, G., \& Matelli, M. (2003). Two different streams form the dorsal visual system: Anatomy and functions. Experimental Brain Research, 153(2), 146-157.

Roux, V., Bril, B., \& Dietrich, G. (1995). Skills and learning difficulties involved in stone knapping. World Archaeology, 27(1), 63-87.

Roux, V., \& David, E. (2005). Planning abilities as a dynamic perceptual-motor skill: And actualistic study of different levels of expertise involved in stone knapping. In V. Roux, \& B. Bril (Eds.), Stone knapping: The necessary conditions for a uniquely hominin behaviour (pp. 91-108). Cambridge: McDonald Institute for Archaeological Research.

Schick, K. D. (1987). Modeling the formation of Early Stone Age artifact concentrations. Journal of Human Evolution, 16, 789-807.

Schick, K. D., Toth, N., Garufi, G., Savage-Rumbaugh, E. S., Rumbaugh, D., \& Sevcik, R. (1999). Continuing investigations into the stone tool-making and tool-using capabilities of a bonobo (Pan paniscus). Journal of Archaeological Science, 26, 821-832.

Schmahmann, J. D. (1996). From movement to thought: Anatomic substrates of the cerebellar contribution to cognitive processing. Human Brain Mapping, 4, 174-198.

Schmahmann, J. D. (1997). The cerebellum and cognition. New York: Academic Press.

Schmahmann, J. D., Doyon, J., Toga, A. W., Petrides, M., \& Evans, A. C. (2000). MRI atlas of the human cerebellum. San Diego: Academic Press.

Semaw, S., Renne, P., Harris, J. W. K., Feibel, C. S., Bernor, R. L., Fesseha, N., et al. (1997). 2.5-Million-year-old stone tools from Gona, Ethiopia. Nature, 385, 333-336. January 231997.

Semendeferi, K., Armstrong, E., Schleicher, A., Zilles, K., \& Van Hoesen, G. W. (2001). Prefrontal cortex in humans and apes: A comparative study of area 10. American Journal of Physical Anthropology, 114, 224-241.

Smitsman, A. W., Cox, R. F. A., \& Bongers, R. M. (2005). Action dynamics of tool use. In V. Roux, \& B. Bril (Eds.), Stone knapping: The necessary conditions for a uniquely hominin behaviour (pp. 129-144). Cambridge: McDonald Institute for Archaeological Research.

Stout, D. (2002). Skill and cognition in stone tool production: An ethnographic case study from Irian Jaya. Current Anthropology, 45(3), 693-722.

Stout, D. (2005). The social and cultural context of stone-knapping skill acquisition. In V. Roux, \& B. Bril (Eds.), Stone knapping: The necessary conditions for a uniquely hominin behaviour (pp. 331-340). Cambridge: McDonald Institute for Archaeological Research.

Stout, D., Quade, J., Semaw, S., Rogers, M., \& Levin, N. (2005). Raw material selectivity of the earliest stone toolmakers at Gona, Afar, Ethiopia. Journal of Human Evolution, 48(4), 365-380.

Stout, D., Toth, N., Schick, K., Stout, J., \& Hutchins, G. (2000). Stone toolmaking and brain activation: Positron Emission Tomography (PET) studies. Journal of Archaeological Science, 27(12), 1215-1223.

Suwa, G., White, T. D., \& Howell, F. C. (1996). Mandibular postcanine dentition from the Shungura Formation, Ethiopia: Crown morphology, taxonomic allocations, and Plio-Pleistocene hominid evolution. American Journal of Physical Anthropology, 101(2), 247-282.

Tomasello, M. (1999). The cultural origins of human cognition. Cambridge, MA: Harvard University Press.

Toth, N., \& Schick, K. (1993). Early stone industries and inferences regarding language and cognition. In K. Gibson, \& T. Ingold (Eds.), Tools, language and cognition in human evolution (pp. 346-362). Cambridge: Cambridge University Press.

van Schaik, C. P., Deaner, R. O., \& Merrill, M. Y. (1999). The conditions for tool use in primates: Implications for the evolution of material culture. Journal of Human Evolution, 36, 719-741. 
Wolpert, L. (2003). Causal belief and the origins of technology. Philosophical Transactions of the Royal Society of London A, 361, 1709-1719.

Wynn, T. (2002). Archaeology and cognitive evolution. Behavioral and Brain Sciences, 25, 389-438.

Wynn, T., \& McGrew, W. (1989). An ape's view of the Oldowan. Man, 24, 383-398.
Zilles, K. (2005). Evolution of the human brain and comparative cyto- and receptor architecture. In S. Dehaene, J.-R. Duhamel, M. D. Hauser, \& G. Rizzolatti (Eds.), From monkey brain to human brain: A Fyssen Foundation symposium (pp. 41-56). Cambridge, Massachusetts: MIT Press. 